\title{
Role of Tree Breeding in Timber and Wood Supply in World and India: Status and Outlook
}

\author{
Ram Bichari Thakur ${ }^{1}$ and Prof. Dr. Joachim Schmerbeck ${ }^{2}$ \\ Corresponding author: Ram Bichari Thakur \\ Email: rbthakur@gmail.com
}

\begin{abstract}
Tree breeding is an important component of tree improvement which involves the application of genetic principles for the mass production of seedlings with desired traits in order to achieve higher productivity, better adaptability of the environment and vigorous growth rate. It helps in increasing yields and shortened rotations so it has a large potentiality to supply timber and wood demand of the world. Species choice, provenance selection and propagation method are the major aspects of tree breeding. Plus tree selection, progeny testing, provenance test and vegetative propagation have been used since early of civilization and often regarded as conventional tree breeding techniques while seed orchards, clonal propagation, somatic embryogenesis, micro-propagation or in-Vitro propagation, and biotechnology are modern tree breeding techniques. Different countries have been developing tree breeding techniques and achieving maximum benefits from it. Southeast Asia is using Acacia mangium, A. crassicarpa, Gmelina arborea, and Eucalyptus spp.; Populus deltoids, Casuarina equisetifolia, Eucalyptus spp. have been using by India; Teak has been vegetative propagated in Thailand; Salix babylonica has been growing in Greece for biomass production. Increasing yield and shortened rotation are the major prospects while loss of genetic diversity, higher production costs and requirement of constant upgrading are the major hindrances of tree breeding.
\end{abstract}

Key Words: Hybrids, Seed orchards, Micro-propagation, Biotechnology, Tree Improvement

\section{Introduction}

Tree breeding is the application of genetic principles to the genetic improvement and management of forest trees (http://en.wikipedia.org/wiki/Tree_breeding).

Success in the establishment and productivity of forestry plantations is determined largely by species used and the source of seed within species(Zobel and Talbert, 1984 as cited in

${ }^{1}$ M.Sc. Natural Resource Management, TERI University, New Delhi

${ }^{2}$ Assistant Professor, TERI University, New Delhi 
White, Adams and Neale, 2007 and also on http://www.westcoastpaper.com/images/docs/ captive_plantation.pdf).

\section{Linkages of Tree Breeding with Tree Improvement}

Tree improvement most often has relied on traditional breeding techniques like selection of superior (plus candidate) trees for volume and stem straightness, and grafting these into breeding orchards and producing seed orchards. When breeding orchards begin to flower, pollination of selections is artificially controlled, seeds are collected, progeny tests are established, and the best offspring are chosen for the next cycle of breeding. At the same time, selections whose offspring did not perform well in the progeny tests are removed from the production seed orchards to improve genetic quality (Tridasa, Hoon and Cheol, 1996). Success of tree improvement depends upon tree breeding, silviculture and molecular genetics of species and its particular varieties.

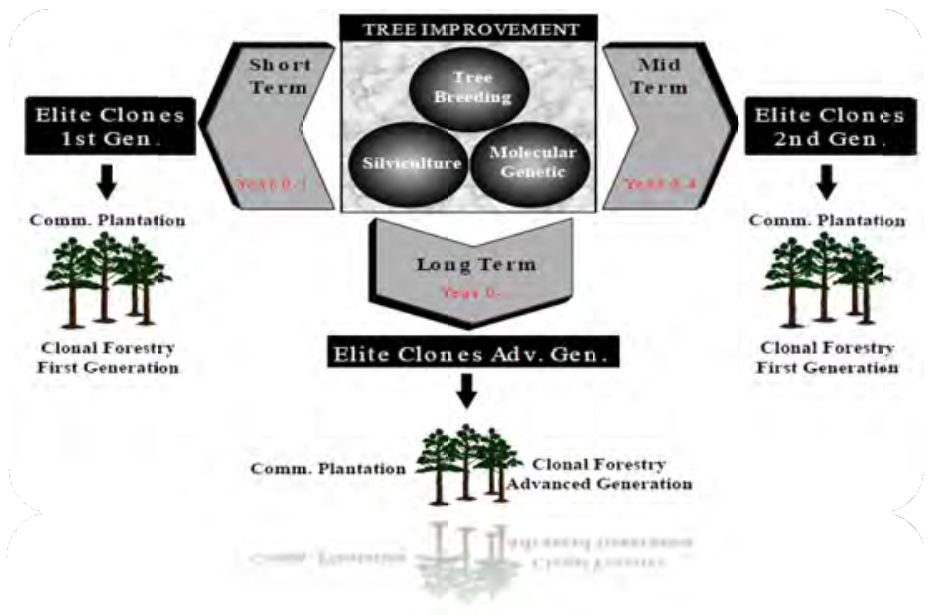

\section{Goal of Tree Breeding}

Tree breeding helps in genetic adjustment of plants to the service of humans, and capitalizes the natural variability and packages of the best traits (Zsuffa, 1989 as cited in Chuntanaparb and Ranganathan, 1981). It consists of packaging the desired traits into improved individuals, mass production of improved individuals for planting purposes and developing and maintaining a genetic base population for advanced generation.

\section{Importance of Tree Breeding}

Tree breeding helps in increasing yields and shortened rotations, so planted forests become increasingly attractive as an investment for producing industrial wood, and it can ensure supplying of fuel wood as well as meet other needs of rural people if introducing fast-growing multi-purpose tree species for farmland planting (Shea and Carlson, 1984). 
The principles and practices of plant breeding of trees are well established and they apply equally to industrial plantations and small land-holder agroforestry and community plantations also. The goal of tree improvement for agroforestry is to increase the effectiveness of land for productivity, suitability and sustainability of land use for rural communities (www.westcoastpaper.com/images/docs/captive_plantation.pdf). There are a number of key problems or needs that can be addressed by appropriate use of multipurpose tree species through tree breeding strategy. In the Asian region, about 600 million people are experiencing an acute shortage of fuel wood. Either animal dung or crop residues are widely used for fuel or for maintaining and improving agricultural soil fertility. Breeding programs of fastgrowing multi-purpose tree species for farmland planting can ensure supplying of fuel wood as well as meet other needs of rural people (Chuntanaparb and Ranganathan, 1981).

\section{Essential features for Tree Breeding}

Choosing appropriate species and sources is the single most important genetic decision in Tree Breeding. The largest, cheapest, and fastest gains in most tree breeding can be made by using proper species and seed sources within the species (Zobel and Talbert, 1984 cited in White, Adams and Neale, 2007). The wrong choice can lead to loss in productivity or at worst, complete plantation failure (White, Adams and Neale, 2007).

A list of components which are of almost universal importance for tree breeding are listed below (Koski and Vihera-Aarnio, 1986 as cited in Yangchuk, 1994);

I. High rate of net photosynthesis;

II. Efficient light interception;

III. Full utilization of the growing season;

IV. High harvest index;

V. Efficient use of water and nutrients;

VI. Rapid juvenile growth;

VII. Tolerance to competition;

VIII. Tolerance to abiotic stress;

IX. Freedom from pests and diseases;

X. Suitable biomass properties; and

XI. Ease of reproduction and plantation establishment

\section{Types of taxa and their attributes for plantations:}

\section{i) Native versus exotic species}

Native species offers some advantages if a local provenance is used, then adaptation to the climate and soils of the planting zone is ensured. There are many examples in the world of large successful plantation based on native species: Pseudosuga menziesii in the western USA and Canada; Pinus taedaand P. elliottii in the southern USA, Pinus sylvestris and 
Picea abies in Europe and Tectona grandis in India. There are many excellent examples of successful exotic plantations: Picea sitchensis, Pinus contorta, Pseudosuga menziesii, and Eucalyptus globulus are planted on a large extent in different parts of Europe. The two most widely planted exotic tree species in the world are Eucalyptus grandis and Pinus radiate (White, Adams and Neale, 2007).

\section{ii) Interspecific Hybrids}

Hybrid vigor possesses the superiority of hybrid over parental species. Moreover, it is ease of vegetative propagation of hybrid clones and popularity of hybrids in plantation of many genera includes Populus, Salix and Eucalyptus (White, Adams and Neale, 2007).

\section{iii) Subspecies, varieties, provenances and land races}

Genetic differentiation within each variety or sub species can be great, necessitating consideration of them as separate entities and field testing of many provenances or sources are required (White, Adams and Neale, 2007).

\section{Tree breeding techniques}

Tree breeding is a continuous process and assumed that it might be started from the early period of civilization. Both conventional and modern methods are being applied in the tree breeding.

Some conventional tree breeding techniques are listed below:-

I. Plus tree selection

II. Progeny testing

III. Provenance test

IV. Vegetativepropagation

Some modern tree breeding techniques are listed below:-

I. Seed orchards

II. Clonal propagation

III. Somatic Embryogenesis

IV. Micro-propagation or In-Vitro propagation

V. Bio technology

\section{Some conventional tree breeding techniques}

I. Plus tree selection

"Tree breeder usually select individual trees that are phenotypically superior in respect to the traits" (Yanchuk, 1998). Squillace, 2005 states, "If environmental effects are strong, 
offspring-parent regression will tend to be weak and genetic gains will tend to be small. Similarly, if the environmental effects are weak, parent-offspring regression will tend to be strong and genetic gains will be large. According to Jonathan, 2003, desired qualities/ traits can be readily achieved through plus-tree selection and resulting genetic gains up to $15 \%$ in height and diameter growth, and up to $35 \%$ in volume per unit area.

\section{Progeny testing}

Progeny testing refers to estimate the relative genetic values of parents based onperformance of their offspring. Parental selection through progeny performance is called backward selection since data from progeny are used to rank and re-select top parents (Werner and Josefina, 2001).

The pre-requisite for progeny testing are as follows:-

$>$ Plus trees whose progeny perform consistently well,

$>$ Must have superior breeding values and

$>$ Favored for inclusion in the breeding and propagation populations.

\section{Provenance test}

"A very strong differentiation of adaptive traits can be found among tree populations growing under different ecological conditions. Such variabilities are characteristic of provenances and may be expressed by various traits on the genetic, morphological, phenotypic and phenological levels which can be obtained by submitting provenances to specific testing procedures" (Eriksson 1996, 1998 cited in Werner and Josefina, 2001).

Prof. Champion initiated provenance trial test of Chir Pine at Dehradun,India during 1930s. He realized the importance of geographical variations, and applied the knowledge of forest genetics (http://fri.icfre.gov.in).

\section{Vegetative Propagation}

Vegetative propagation of plant has been carried out through using vegetative tissues, resulting genetically identical to the original "donor" plant. Vegetative Propagation is one of the most important tool and widely used in tree breeding to manage breeding population more effectively. It has major advantage over sexual reproduction as a means of mass production. All the genetic components of "donor" plant can becaptured and duplicated (www.westcoastpaper.com/images/docs/captive_plantation.pdf).

Vegetative Propagation occurs both naturally and artificially:-

- Natural vegetative propagation: Many plants spread through rhizomes, corms, bulbs, tubers and runners.

- Artificial vegetative propagation: grafting, cutting and tissue culture. 
Huge leap in short rotation plantation productivity offered by specific hybrids have beenmade operationally possible through the development of technique of vegetative propagation by cutting. The main advantages and importance of vegetative propagated Eucalyptus, Acacia, Pines and Poplars etc. are namely uniformity, adaptation, cost and wood productivity (www. westcoastpaper.com/images/docs/captive_plantation.pdf).

Mass vegetative propagation has become an important tool for increasing thecompetitiveness of the forestry based industry. This method reaches its highest potential when it is used to establish clonal forests of hybrids endowed with better wood quality and higher volumetric growth (Teotônio, et al. 2004).

\section{Some modern tree breeding techniques-}

\section{Seed Orchard}

A seed orchard is an intensively-managed plantation of specifically arranged trees for the mass production of genetically improved seeds to create plants, or seeds for the establishment of new forests. Seed orchard is a common method of mass-multiplication for transferring genetically improved material from breeding populations. It is a plantation of genetically superior trees where favoured trees are isolated to reduce pollination from genetically inferior ones, intensively managed to produce frequent, abundant, and easily harvested seeds; and designed and managed to produce seeds of superior genetic quality compared to those obtained from seed production areas, seed stands, or unimprovedstands (http://en.wikipedia. org/wiki/Seed_orchard).

There are two main types of seed orchards regarding to the way of establishing (Kyu-Suk Kang, 2001 cited in Tellalov, 2006):-

Seedlings seed orchards, which have been grown from seeds collected form plustrees and having large genetic base.

$>$ Clonal seed orchards, which have been grown either from grafts or from rootedcuttings

\section{Clonal propagation}

Clonal propagation offers several advantages over traditional seedling establishmentpractices, including planting stock and product uniformity, alternative disease management strategies, vegetative propagation of conifers and potential to capture greater amounts of the genetic variation (Tuskan, 2002).

Most of the world's large successful cloning emerged through using juvenility of the tissues of trees such as eucalyptus (Eucalyptus sp.), poplars (Populus sp.) willows (Salix sp.), Chinese fir (Cunninghamia lanceolata) and Acacia hybrid (Tuskan, 2002). 


\section{Somatic Embryogenesis for Clonal Forestry}

Somatic embryogenesis (SE) in conifers is a recently developed cloning technique, anunlimited number of genetically identical copies of trees can be produced from a single seed which can offset deficit in genetically superior and high-value trees by deploying the best available genetic stock to commercial sites (www.fao.org/DOCREP/ARTICLE/WFC/ XII/0221-B2.HTM).

\section{Micro-propagation or In-Vitro propagation}

It is the practice of rapidly multiplying stock plant material to produce a large number of progeny plants; used to multiply novel plants, such as those that have been genetically modified; used to provide a sufficient number of plantlets for planting from a stock plant which does not produce seeds, or does not respond well to vegetative reproduction (http:// en.wikipedia.org/wiki/Micropropagation). Some widely used micro-propagation techniques are in Fagus, Eucalyptus, Acacia, Aegle etc (http://www.fao.org/docrep/006/ad223e/ AD223E05.htm).

\section{Biotechnology}

Biotechnology comprises any technique that uses living organisms to make or modify a product, to improve plants or animals, or to develop micro-organisms for a specific use (Haines 1994, 1994a cited by Sedjo, 1999). Currently, biotechnology refers to the commercial application of living organisms or their products, which involves the deliberate manipulation of their DNA molecules (Sedjo, 1999).

The creation of transgenic trees will be commercially attractive if a few transgenic plants can provide the basis for large-scale, low-cost propagation. This is likely to be possible only through some type of low-cost cloning, which will allow replication of transgenic plants. However, replication for some tree species has been shown to be relatively easy. For example, improved hardwoods, such as hybrid poplars, are readily replicable through simple vegetative propagation (Sedjo, 1999).

\section{Major contribution of Tree Breeding in supplying timber and wood in World \& India}

The southern US has greatest potential lies in intensively managed pine plantations, growth of $4 \mathrm{~cd} / \mathrm{ac} / \mathrm{yr}$ (chord per acre per year) can be achieved from good sites with tree breeding and intensive silviculture, even on marginal sites, growth rates of $2 \mathrm{~cd} / \mathrm{ac} / \mathrm{yr}$ can be achieved (Kellison, 2005).

The wood resource for pulp mills in Southeast Asia is primarily from plantations of Acaciamangium, A. crassicarpa, Gmelina arborea, and Eucalyptus spp. Plantation tree growth rates of $25 \mathrm{~m}^{3} / \mathrm{ha} / \mathrm{yr}$ are harvested at an age of 6 year. With genetic improvement and tree breeding, average growth rates of $35 \mathrm{~m}^{3} / \mathrm{ha} / \mathrm{yr}$ are being anticipated (Kellison, 2005). 
The average productivity of poplar under agroforestry system is $20-25 \mathrm{~m}^{3} / \mathrm{ha} / \mathrm{yr}$, which is five times higher than traditional forest throughout Punjab, Haryana, UP and some parts of Bihar, West Bengal and Assam state (Singh et al., 2001 cited in Swamy, et al.2005)

A tree breeding program initiated with C. equisetifolia in Andhra Pradesh at the Regional Forest Research Centre (RFRC) of Rajahmundry in 1994. Plus-trees have been selected and clonally propagated, progeny and clonal tests have been established, primary species selected for the establishment of shelterbelts, established at an initial stocking of 2500 trees/ ha and managed on a 7-year rotation (Prasad and Dieters, 1998).

In Thailand, tree breeding through vegetative propagation of Teak has been given highpriority with great success. Tissue-culture technique of teak has developed on a commercial scale in Thailand (Kaosa-ard et al., 1987; Kaosa-ard, 1990; Kaosa-ard, 1993). Price for this planting stock is approximately two to three times higher than the price for traditional seedlings and/ or stumps. However, combination of tissue culture and subsequent cutting of tissue-culture plantlets proved to be both technically and economically feasible for large scale production of clonal planting material (Apichart K., Verapong S. and Erik D. K, 2000).

Breeding of Salix babylonica of clonal selection for biomass production has been established in Greece. The production of plantation yielded $30 \mathrm{t}$ per ha per year, which was comparatively very high than poplar plantation, and it has high potential for future development of biomass producing clones, and it is more tolerant in a wide variety of climatic and soil conditions (Aravanopoulos, 2010).

Cloning of Poplar in Greece for biomass or wood production is largely successful. More than 100 intra- and interspecific crosses of Poplar have been included in tree breeding. The best clone of Poplar is P. xeuramericana with an average production of 16.54 ton per hectare per year (t/ha/yr) followed by I-214 with an average production of $14.40 \mathrm{t} / \mathrm{ha} / \mathrm{yr}$. (Aravanopoulos, 2010).

\section{Critical analysis and outlook}

\section{Prospects of Tree Breeding}

Forest productivity can be increased significantly through clonal forestry.Some tree species such as Eucalyptus, Poplar and Acacias have already shortened the harvesting cycle through tree breeding and tree improvement programs. This shortened rotation can harvest after five years without sacrificing the quality of wood. The current findings suggest that wood density or pulp yield is independent of growth rate. Increasing yield per hectare and reducing the unit cost of wood may boost up Sustained Commercial Forestry in near future

(www.westcoastpaper.com/images/docs/captive_plantation.pdf). 


\section{Problems of tree breeding}

Loss of genetic diversity, competition between clones and clone specific silviculture required are the major biological concerns. Production/ management costs, propagule costs higher and clonal testing costs as great and requires constant upgrade are the major economic concerns. Social acceptance and regulation are the prime social and environmentalconcerns (www. forestry.gov.uk/pdf/f_d-thompson.pdf/.../f_d-thompson.pdf).

\section{Conclusions}

Tree breeding helps in mass production of seedlings for achieving higher productivity oftimber and wood products. Both conventional and modern techniques have been used for tree breeding in global and Indian level. It assists in supplying large quantities of timber and wood for growing enormous demand of wood market across the world including India. Since modern tree breeding techniques are advancing each day, it has a great potentiality to supply large biomass demand of the world including India.

\section{Reference}

Apichart, K., Verapong, S. and Erik, D. K. 2000. Experience from Tree Improvement of Teak (Tectonagrandis) in Thailand

Aravanopoulos, F.A. 2010. Breeding of fast growing forest tree species for biomass production inGreece. b i o m a s s and b i o e n e r gy 34 ( 2010 ) 153 1e1 537. http://www.elsevier.com/locate/biombioe

Blush, T.D. Characterizing reproductive phenology of seed orchard clones. Tree improvementscientist, genetics group, Westvaco Forest Science Laboratory, Summerville, South Carolina

Chuntanaparb, L. and Ranganathan, R. 1981. Defining tree breeding objectives for multipurpose treespecies in Asia: Report no. 10. Winrock International F/FRED P.O. Box 1038 Kasetsart University Bangkhen, Bangkok 10903, Thailand

Dvorak, W.S. 2001. The improvement and breeding of Pinus patula. CAMCORE Cooperative, Collegeof Forest Resources, North Carolina State University, Raleigh, NC, 27695, USA. 53

Ginwal, H.S. 2009. Provenance and family variation in growth performance of Eucalyptus tereticornis(Sm.) in a provenance cum progeny trial in Midnapore, India. Forest Ecology and Management 258 (2009) 2529-2534. _ 2009 Elsevier B.V. All rights reserved. www.elsevier.com/locate/foreco. 
Jonathan, C. 2003. The effectiveness of plus-tree selection for yield. Centre for Research and Teachingin Tropical Agronomy (CATIE)/UK Overseas Development Administration, Turrialba, Cartago, CostaRica

Kellison, R.C. 2005. Production forestry into the $21^{\text {st }}$ century: A world view. Champion InternationalCorporation, 1316 Dixie Trail, Raleigh, NC 27607

Micropropagation for quality propagule production in plantation forestry http://nopr.niscair. res.in/bitstream/123456789/5843/1/IJBT\%203(2) \%20159-170.pdf http://www.fao. org/docrep/005/ac777e/ac777e08.htm

Prasad, N.S. and Dieters, M.J. 1998. Genetic control of growth and form in early-age tests of Casuarina equisetifolia in Andhra Pradesh, India. Forest Ecology and Management 110 (1998) 49-58. Elsevier Science B.V. All rights reserved.

Reforestation, Nurseries and Genetics Resources www.rngr.net/publications/wpsm/ chapter2/at_download/file

Sedjo, R. 2001. Biotechnology's potential contribution to global wood supply and forest conservation.Resources for the Future, 1616 P Street, NW, Washington, D.C. 20036, Internet:http://www.rff.org

Shea, K.R. and Carlson, L.W. 1984. Increasing productivity of multipurpose tree species: A blueprint for action. International Union of Forestry Research Organizations (IUFRO) Planning Workshop for Asia, 16-28 July 1984

Squillace, A. E. Where we stand on techniques and seed orchard culture: selection of superior trees.Principal Plant Geneticist, Naval Stores and Timber Production Laboratory, South eastern Forest Experiment Station, Forest Service, U. S. Department of Agriculture, Olustee, Florida.

Swamy, S.L., Mishra, A. and Puri, S. 2005. Comparison of growth, biomass and nutrient distribution infive promising clones of Populus deltoides under an agrisilviculture system. 2005 Elsevier Ltd. Bioresource Technology 97 (2006) 57-68.

Teak improvement in Indonesia - Dr. Hendi Suhaendi http://www.fao.org/DOCREP/005/ AC773E/ac773e0c.htm

Tellalov, Y. 2006. Relative female reproductive output of grafted Scots pine (Pinus sylvestristris) clones planted on different places. Department of Forest Genetics and Plant Physiology, Swedish University of Agricultural Sciences, S-901 83 Umea, Sweden 
Teotônio, F.A., Fett-Neto, A.G. and Alfenas, A. C. 2004. Current techniques and prospects for theclonal propagation of hardwoods with emphasis on Eucalyptus. Plantation Forest Biotechnology for the 21st Century, 2004: 303-333 ISBN: 81-7736-228-3

The wood fuel scenario and policy issues in india www.ces.iisc.ernet.in/energy/ HC270799RWEDP/acrobat/fd49.pdf

Tissue culture of forest tree species : recent researches in INDIA http://www.rngr.net/ publications/tree-improvement-proceedings/sftic Forest genetics and tree improvement research in India idl-bnc.idrc.ca/dspace/bitstream/10625/12734/1/97797.pdf

Tree breeding - Wikipedia, the free encyclopedia en.wikipedia.org/wiki/Tree_breeding

Tree improvement through clonal forestry www.westcoastpaper.com/images/docs/captive_plantation.pdf

Tree improvement through clonal forestry: the west coast paper mills experience. www.westcoastpaper.com/images/docs/captive_plantation.pdf

Tridasa, A.M., Hoon, K. and Cheol, K.Y. 1996. Increasing yield and quality improvement through clonalforestry and breeding program, Case Study in PT. Korintiga Hutani. PT Bio Hutanea - Jakarta and PT Korintiga Hutani

Werner D. Maurer and Josefina Fernández-López. 2001. Establishing an international sweet chestnut(Castanea sativa Mill.) provenance test: preliminary steps. For. Snow Landsc. Res. 76, 3: 482-486(2001)

White, T.L., Adams, W.T. and Neale, D.B. 2007. Forest Genetics. CABI Publishing, 875 MassachusettsAvenue, $7^{\text {th }}$ Floor, Cambridge, MA 02139, USA

Yanchuk, A.D. 1994.Techniques in forest tree breeding. Forests and Forest PlantsVol. III- Techniquesin Forest Tree Breeding Tree improvement http://www. encyclopediaofforestry.org/index.php?title=BioEco11 